\title{
Extreme emulsification: formation and structure of nanoemulsions
}

\author{
T.G.Mason ${ }^{* 1,2}$, S.M.Graves ${ }^{1}$, J.N.Wilking ${ }^{1}$, M.Y.Lin ${ }^{3}$ \\ ${ }^{1}$ Department of Chemistry and Biochemistry, University of California - Los Angeles, \\ 607 Charles E Young Dr. East Los Angeles, CA 90095 USA \\ 2 Department of Physics and Astronomy, University of California - Los Angeles, \\ 607 Charles E Young Dr. East Los Angeles, CA 90095 USA \\ ${ }^{3}$ Center for Neutron Research, National Institute of Standards and Technology, \\ Gaithersburg, MD 20899 USA
}

Received July, 18, 2005, in final form November 24, 2005

\begin{abstract}
Nanoemulsions are metastable dispersions of nanodroplets of one liquid that have been ruptured by shear in another immiscible liquid. The ruptured droplets are stabilized against subsequent coalescence by a surfactant. Because the nanodroplets do not form spontaneously, as they can in lyotropic "microemulsion" phases, the structure of nanoemulsions is primarily dependent on the history of the applied shear stresses relative to the interfacial restoring stresses. By applying extremely high shear rates and controlling the composition of the emulsion, we have been able to rupture microscale droplets down to diameters as small as $30 \mathrm{~nm}$ in a microfluidic process that yields bulk quantities suitable for commercial production. Following ultracentrifugal fractionation to make the droplets uniform, we study the structure of these emulsions using small angle neutron scattering (SANS) at dilute and concentrated volume fractions. We contrast the structure of a concentrated nanoemulsion with the structure factor of hard spheres at a similar volume fraction.
\end{abstract}

Key words: emulsion, nanoemulsion, droplet, nanoscale, rupturing, microfluidics, form factor, structure factor, fractionation

PACS: $82.70 . K j, 61.46 .-w, 61.12 . E x$

\section{Introduction}

Emulsions are dispersions of droplets of a liquid phase in a different immiscible liquid [1-3]. Oil droplets dispersed in water are known as "direct emulsions", whereas water droplets dispersed in oil are called "inverse emulsions". Without shear, emulsions would never form, since the thermodynamic lowest energy state of two immiscible liquids is simply a layer of the liquid having lower density on top of a layer of the liquid having higher density. In order to create emulsions, shear must be applied in a way that causes the droplets of one phase to stretch and rupture, through a capillary instability, into smaller droplets. Stretching and rupturing the droplets is possible if the applied shear stress is greater than the characteristic Laplace pressure scale, $\sigma / a$, where $\sigma$ is the liquidliquid surface tension and $a$ is the droplet's radius. A surfactant, usually soluble in the continuous phase, coats the surfaces of the newly formed droplets and provides a stabilizing repulsion between droplet interfaces that strongly inhibits subsequent recombination, or coalescence, of the droplets. Microscale emulsions can be commonly made in the kitchen using shear stresses generated by whisks, spatulas, and blenders; mayonnaise is a common food emulsion of oil droplets in water stabilized by egg protein. However, obtaining nanoscale emulsions having droplet diameters less than $100 \mathrm{~nm}$ with these methods is generally not possible since the applied shear stresses are too low.

In order to go beyond conventional emulsification methods into the realm of nanoemulsions, it is necessary to apply extremely high shear stresses to cause violent stretching and rupturing of the droplets. By equating the viscous stress of the driving shear with the Laplace pressure

\footnotetext{
*Presenting author
} 
of droplets that no longer rupture in the shear flow, one can obtain the classic Taylor equation for estimating the radius of the emulsion [2-4]: $a \approx \sigma /\left(\eta_{\mathrm{c}} \dot{\gamma}\right)$, where $\dot{\gamma}$ is the shear rate and $\eta_{\mathrm{c}}$ is the viscosity of the continuous liquid phase in which the droplets are dispersed. This formula neglects the dissipative effects of viscosity, $\eta_{\mathrm{d}}$, of the liquid inside the droplets. Since the shear stress depends on a combination of the shear rate and the emulsion's rheological properties, it is possible to make nanoscale emulsions of strongly immiscible liquids without relying upon thermodynamic selfassembly of nanoscale droplets in microemulsion phases [5,6]. Microfluidic and ultrasonic techniques both produce the kind of extreme shear that is required to break emulsions down to diameters below $100 \mathrm{~nm}$ [7-9]. Sub-micron emulsions are sometimes called "mini-emulsions", and we define "nanoemulsions" to be emulsions having diameters around $100 \mathrm{~nm}$ or less [10]. Because the submicroscopic droplet sizes make it difficult to observe the droplets and because very strong shear is required to create them, nanoemulsions have been studied far less than conventional emulsions. Moreover, since it is easier to visualize the rupturing of isolated droplets, most experiments have avoided the complexity inherent in emulsification of concentrated emulsions at a droplet volume fraction $\phi$ where droplet interfaces strongly interact.

We have developed a systematic procedure using a high-pressure microfluidic device to create bulk quantities of oil in water nanoemulsions with diameters as small as $30 \mathrm{~nm}$ [10]. Although the raw nanoemulsions have a peaked monomodal size distribution, as determined by dynamic light scattering, we use ultracentrifugation to fractionate the droplets and make them more monodisperse. Once fractionated, the nanoemulsions are an excellent model system for investigating the structure of concentrated dispersions of deformable droplets using small angle neutron scattering (SANS) [11]. We contrast the structure of a concentrated nanoemulsion with the structure of a concentrated suspension of uniform hard spheres, and we propose some simple, yet speculative, explanations for the differences in the structure.

\section{Experiment}

Silicone oil (polydimethylsiloxane or PDMS) is first dispersed in an aqueous solution of the ionic surfactant, sodium dodecylsulfate (SDS) using a crude blender to create microscale droplets. In this first step, we create a premixed emulsion that has a controlled oil viscosity, $\eta_{\mathrm{d}}$, oil volume fraction, $\phi$, and surfactant concentration, $C$. The premixed microscale emulsion is then used as the input feed to a high-pressure, impinging-jet microfluidic device (Microfluidics). The microfluidic device is driven by compressed air at a pressure, $p$, and creates a pulsed extensional shear flow with peak shear rates, $\dot{\gamma}$, in excess of $10^{8} \mathrm{~s}^{-1}$. We typically process a volume of about $100 \mathrm{ml}$ over less than a minute. Since the flow in the steel microfluidic channel is spatially inhomogeneous, we then take this processed emulsion and feed it back into the microfluidic device several times so that all of the droplets experience the region of peak shear. The number of times the emulsion has been processed through the device is the number of passes, $N$. By varying the air pressure, we can vary the peak shear rate and the sizes of the ruptured droplets. We characterize the resulting volume-weighted radial distribution, $p(a)$, of the emulsion that has been diluted considerably to $\phi \approx 10^{-5}$ using dynamic light scattering (DLS) at 90 degrees. From this, we extract the volume-averaged radius, $\langle a\rangle$.

In order to further improve the uniformity of the size distribution, we use ultracentrifugal fractionation [12]. In the earth's gravitational field, the Brownian motion of the nanodroplets is so strong that gravitational buoyant forces do not cause appreciable creaming, even over long time scales. However, ultracentrifugation can produce such large effective gravitational acceleration that the buoyant forces can overcome the Brownian motion. Ultracentrifugal fractionation is a simple method that relies upon the differences in the creaming rates of small and large droplets when the droplets experience a buoyant force due to the density difference between the oil and water. This density difference is typically about $0.05 \mathrm{~g} / \mathrm{cm}^{3}$, and depends on the molecular weight of the oil. Since the Stokes drag force on a sphere is proportional to $v a$, where $v$ is the steady creaming velocity, and the buoyant force is proportional to $a^{3}$, the creaming velocity is proportional to $a^{2}$, so size separation can be efficient. We dilute the emulsion to $\phi=0.1$ and spin at 20,000 RPM for several hours using a swinging bucket rotor. The solid plug at the top of the centrifuge 
tube is extracted and split into sections, and similar sections from different tubes are recombined. The process can be repeated until the desired degree of uniformity is obtained. The drawback of repeating this process many times is that the volume of the emulsion is reduced by at least a factor of two in each stage of the fractionation.

The small angle neutron scattering measurements have been carried out at the National Institute of Standards and Technology (NIST) in Gaithersburg, MD, USA. The neutron wavelength is $8 \AA$, and we load the nanoemulsions into $1 \mathrm{~mm}$ path length quartz banjo cells. Transmission measurements indicate that only $1.5 \%$ of the neutrons are multiply scattered in the most concentrated samples, so the scattering data are overwhelmingly dominated by single scattering. For concentrated $\phi$, the emulsions are viscoelastic [13], so we use demountable cells to facilitate loading. The range of wavenumbers, $q$, that we choose provides an excellent view of the important features relating to the size and interdroplet structure in concentrated nanoemulsions. The intensity, $I$, as a function of $q$ is calculated by azimuthally averaging the measured intensities from the 2-dimensional neutron array detector around the beam stop center position. We eliminate the data at the lowest $q$ that are affected by the beam stop, and the intensities are reported in absolute units through calibration with known standards.

\section{Results}

We first present results relating to the production and fractionation of the nanoemulsions, and then we describe structural studies of dilute and concentrated emulsions using SANS.

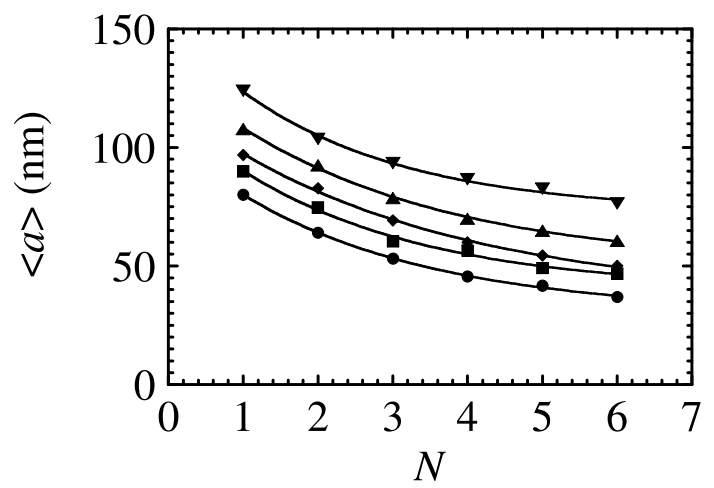

Figure 1. Average droplet radius, $\langle a\rangle$, as a function of the number of passes, $N$, of silicone oil-in-water nanoemulsions having a fixed volume fraction $\phi=0.2$, surfactant concentration, $C=116 \mathrm{mM}$, and oil viscosity $\eta_{\mathrm{d}}=10 \mathrm{cP}$ at the following driving air pressures, $p: 40$ (inverted triangles), 60 (triangles), 90 (diamonds), 115 (squares), 130 (circles). The solid lines are fits to $\langle a(N)\rangle=\left\langle a_{\mathrm{s}}\right\rangle\left[1+g \exp \left(-N / N_{\mathrm{s}}\right)\right]$, as explained in the text.

We have investigated how the peak shear rate affects the droplet sizes for semi-dilute emulsions that are subjected to the strong extensional shear flow. In figure 1, we show the average oil droplet radius obtained from DLS as a function of the number of passes, $N$, for a set of different input air pressures to the microfluidic device ranging from $p=40$ psi to 130 psi. The composition of the premixed emulsion is exactly the same in all cases: $\phi=0.2, C=116 \mathrm{mM}$, and $\eta_{\mathrm{d}}=10 \mathrm{cP}$. The average droplet radius decreases systematically as we increase the peak shear rate through the driving air pressure. Moreover, as $N$ increases, the average radius decreases initially, yet it begins to saturate toward a constant value, $\left\langle a_{\mathrm{s}}\right\rangle$, at the largest $N$ we explore. To characterize the decrease, we fit each $\langle a(N)\rangle$ at a particular pressure to the following empirical equation [10]:

$$
\langle a(N)\rangle=\left\langle a_{\mathrm{s}}\right\rangle\left[1+g \exp \left(-N / N_{\mathrm{s}}\right)\right]
$$

where $g$ is a dimensionless factor related to the ratio of the effective radius at low passes to $\left\langle a_{\mathrm{s}}\right\rangle$ and $N_{\mathrm{S}}$ is the characteristic number of passes where the exponential decrease component has fallen to 
$1 / e$. The solid lines in figure 1 show that the fits provide an excellent description of the reduction in $\langle a(N)\rangle$ at all measured pressures. For all of the different pressures, the shape is not very different: $N_{\mathrm{s}}$ ranges from 2 to 3 and $g$ ranges from 1 to 2 . At six passes the measured $\langle a\rangle$ are within $20 \%$ of the saturation radii, so it is not possible to cause a significant reduction in $\langle a\rangle$ beyond $N \approx 6$ with this particular composition, regardless of the pressure. The origin of the reduction and saturation of $\langle a(N)\rangle$ remains speculative, yet one hypothesis, which is at least qualitatively consistent with our results, is that the shear flow in the microfluidic device is both spatially and temporally varying. This is due to the pulsing flow that drives the emulsion through the microchannels. The fluid velocities must be lower near the walls, so only a fraction of the total volume of the emulsion experiences the peak shear rate in any given pass. It is clear that higher shear rates yield the smallest droplets. However, over the limited range of pressures we have studied, we find that $\left\langle a_{\mathrm{s}}\right\rangle$ does not vary inversely with the pressure and, therefore, shear rate, as one might expect from simple rupturing of isolated droplets in strictly controlled viscous shear flows. For an increase in pressure of about a factor of three, we find only a reduction of about a factor of two in $\left\langle a_{\mathrm{s}}\right\rangle$. The origin of this deviation from the Taylor estimate may arise from the increasingly important role of the dispersed phase viscosity as the droplets become smaller.

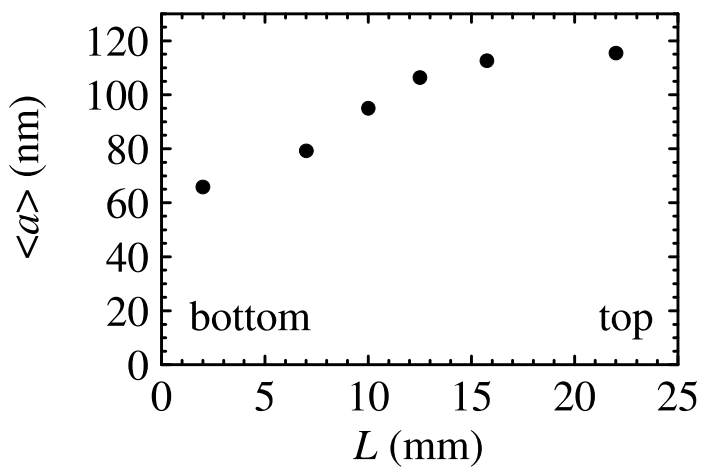

Figure 2. Average droplet radius, $\langle a\rangle$, as a function of length, $L$, along the solid plug of concentrated emulsion after ultracentrifuging a silicone oil-in-water emulsion at 20,000 RPM for 3 hours. Small and large $L$ correspond to the bottom and top of the plug, respectively.

As an example of the size separation that can be obtained from additional ultracentrifugal fractionation after microfluidic emulsification, we present the average radius of the droplets as a function of length, $L$, along one of the solid plugs that we have extracted from the top of the tube in figure 2. The composition of the emulsion before centrifugation has been set at $\phi=0.1$, $\eta_{\mathrm{d}}=10 \mathrm{cP}$, and $C=58 \mathrm{mM}$. As the emulsion is spun at 20,000 RPM, a solid plug forms at the top of the centrifuge tube, and essentially no droplets are remaining in the aqueous solution below. At the top of the plug, we find larger droplets that have creamed rapidly, and at the lower part of the plug, we find smaller droplets that have taken longer to cream. The range of average droplet radii shown in the plot is rather small, from about $60 \mathrm{~nm}$ to about $120 \mathrm{~nm}$, since the unfractionated nanoemulsion exciting the microfluidic device is not very polydisperse.

In figure 3, we show the form factors, $F(q)$, of several different nanoemulsions that have been ultracentrifugally fractionated three times, measured using SANS. All of the data shown are for $\phi \leqslant 0.01$ so that interference effects from neighboring droplets is minimal and the scattering is just related to the Fourier transform of a sphere, averaged over the droplet size distribution. At low $q$, a flat plateau is visible. Toward higher $q$, there is a primary shoulder providing the characteristic droplet size, and a secondary shoulder at even higher $q$ is visible. The evidence of the primary and secondary shoulders indicates that our emulsions are quite uniform. Except for the smallest droplets, the minimum in $F(q)$ expected between the two shoulders for perfectly monodisperse spheres is largely smeared out due to the droplet polydispersity, and, to a lesser degree, by the width of the neutron wavelength distribution. The solid lines in figure 3 are fits to the data using a model of hard spheres [14] having a polydisperse Schulz distribution. The smallest polydispersity 


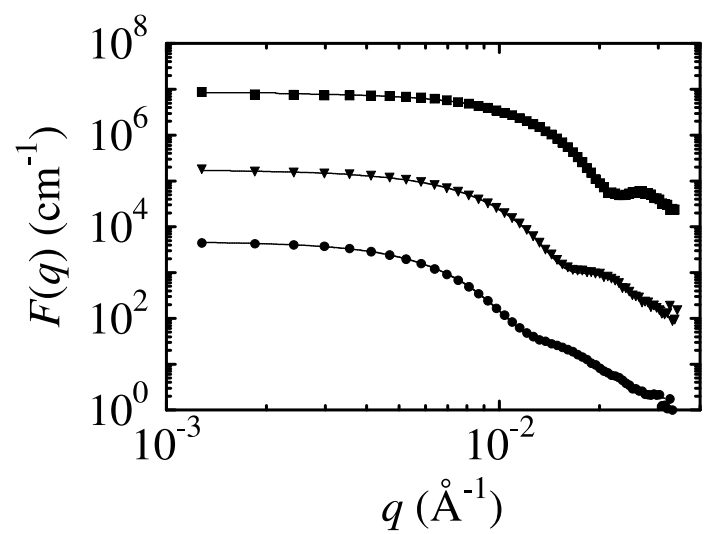

Figure 3. Form factor, $F$, as a function of wavenumber, $q$, for three different silicone oil-in-water nanoemulsions after ultracentrifugal fractionation. The intensities of the top and middle curves have been multiplied by $10^{4}$ and $10^{2}$, respectively, to make them easier to view. Solid lines are fits to a Shultz distribution of polydisperse hard spheres, and the results of the fit give the following average radius, $\langle a\rangle$, and polydispersity, $\delta a /\langle a\rangle: 20 \mathrm{~nm}$ at $13 \%$ (squares), $27 \mathrm{~nm}$ at $16 \%$ (inverted triangles), and $33 \mathrm{~nm}$ at $21 \%$ (circles).

that we observe is $13 \%$, corresponding to the smallest droplet radius of $\langle a\rangle=20 \mathrm{~nm}$. This is definitive proof that we have obtained bulk quantities of a very uniform dispersion of nanoscale oil droplets in water. The smallest nanoemulsion we have observed with SANS has $\langle a\rangle=15 \mathrm{~nm}$.

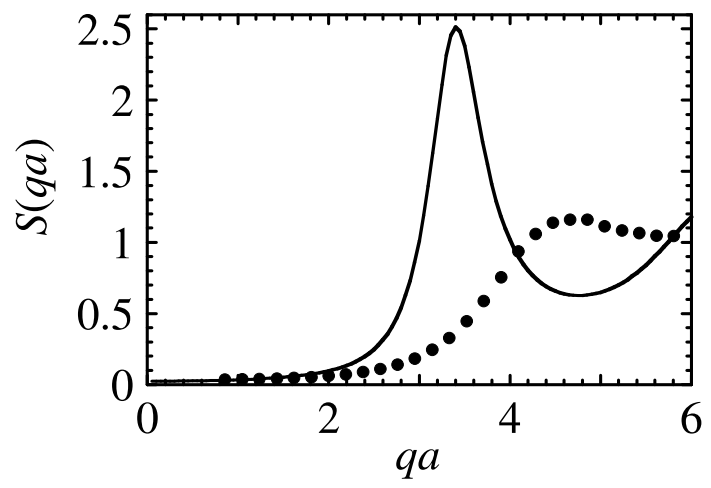

Figure 4. Structure factor, $S$, as a function of dimensionless wavenumber, $q a$, for nanoemulsion droplets having $\langle a\rangle=75 \mathrm{~nm}$ at a droplet volume fraction, $\phi=0.46$ (solid circles). The solid line is the theoretical prediction for disordered hard spheres using the Percus-Yevick approximation at $\phi=0.45$. The peak for nanoemulsion droplets is much weaker and occurs at higher $q a$ than the peak for hard spheres.

In addition to examining the form factor of dilute nanoemulsions, we have also used SANS to study the structure of a concentrated nanoemulsion. In figure 4 , we show the structure factor, $S(q a)$, of a nanoemulsion having $\langle a\rangle=75 \mathrm{~nm}, \phi=0.46$, and $C=10 \mathrm{mM}$. This structure factor has been obtained by dividing the measured intensity, $I(q a)$, of the emulsion at $\phi=0.46$ with the form factor, $F(q a)$, obtained at dilute $\phi$. The two dimensional scattering pattern shows a ring, indicating that the overall droplet structure is not crystalline, but is disordered, as in a glass [15]. At the lowest $q a, S(q a)$ is much less than one, indicating that droplets are repelled from their neighbors. At higher $q a$, the structure factor exhibits a small nearest-neighbor peak, indicating that there is a small degree of correlation of the centers of neighboring droplets. However, the peak value of $S$ for nanoemulsions is much lower than that of perfectly monodisperse hard spheres at essentially the same $\phi$ (see figure 4). Presumably, nanoemulsions stabilized by ionic surfactants would interact through Debye-screened repulsions, not hard repulsions, so it is not surprising that the experiment 
does not match the prediction. However, the nature of the shift in the $q$ value associated with the peak remains mysterious. The differences between the two plots are not yet well understood theoretically, yet it is unlikely that the residual polydispersity of the droplets could account for all of the differences in the magnitude and positions of the peaks [16].

\section{Discussion}

Microfluidic production can be used to produce silicone oil-in-water nanoemulsions that have radii down to about $15 \mathrm{~nm}$. Due to spatially inhomogenous flow in the microfluidic device, multiple passes of the emulsion are generally required to cause all droplets to experience the region of highest shear and, thus, to obtain a more uniform distribution of smaller droplets. Through dilution and centrifugation of the nanoemulsion, it is possible to independently control $\phi$ and $C$. Moreover, ultracentrifugal size fractionation is effective in creating nanoemulsions having polydispersities approaching $10 \%$. After emulsification and fractionation, the nanoemulsion can be manipulated to alter the composition without changing the droplet sizes. Thus, we have demonstrated that controllable model systems of deformable nanoscale droplets for scientific studies are possible in bulk quantities without relying upon swollen lyotropic micellar phases. The nanoscale droplets are stable, robust, and long-lived, provided the molecular weight of the oil is large enough to prevent coarsening of the droplet sizes through the diffusive transport of oil molecules from one droplet to another through the continuous aqueous phase. It is possible to make nanoscale droplets of oils having viscosities as high as $1000 \mathrm{cP}$, although the smallest droplets are generally obtained with lower viscosity oils. Thus, nanoemulsions represent the extreme limit of metastable liquid droplet dispersions. We believe that it is possible to make stable droplets having radii smaller than $10 \mathrm{~nm}$ through extreme emulsification, although we do not expect to reach $2 \mathrm{~nm}$, corresponding to the radius of a surfactant micelle. Exploring the limits of extreme emulsification remains an interesting frontier in soft condensed matter physics.

Likewise, the structure of concentrated nanoemulsions is also intriguing. At dilute $\phi$, where droplets are well separated from their nearest neighbors, the droplets are spherical. Since the screening length is only a few nanometers, the charged droplets do not repel strongly except a very short distances between the interfaces. Thus, the neutron scattering pattern of nanoemulsions can be well understood in the same manner as a dilute dispersion of hard spheres, and the form factor of polydisperse hard spheres can be used to fit our data nicely. However, the deformability of the droplets in nanoemulsions can affect the structure at higher volume fractions approaching the glass transition. The glassy disorder can lead to a peak in the structure factor that is not as pronounced as in disordered hard spheres at higher concentrations. Polydispersity alone cannot account for this difference between liquid droplets and hard spheres, and it is possible that the droplet deformability is beginning to alter the scattering as the droplets reach concentrations at which they begin to deform. This deformation may cause a reduction in the extent of spatial correlations of the centers of the droplets that would be seen in $S(q a)$. More work, both experimental and theoretical, is needed to establish the structure of deformable objects that are quenched to high volume fractions where they both jam [17] and deform.

\section{Conclusion}

We have introduced nanoemulsions as metastable droplet dispersions resulting from extreme emulsification, and we have presented some initial structural measurements of fractionated nanoemulsions using small angle neutron scattering. Nanoemulsions are interesting model systems of deformable droplets that are part of the growing array of nanoscale materials. As a model system, concentrated nanoemulsions are particularly interesting for exploring the average structure of biliquid foams. Potential applications in pharmaceutical products, in which control over droplet size and polydispersity is important, appear to be promising. 


\title{
Acknowledgements
}

We thank Dr. John McTague for supporting this research through the McTague Career Development Chair at UCLA. We thank NIST for the NG-7 SANS beam time.

\section{References}

1. Bibette J., Leal-Calderon F., Poulin P., Rep. Prog. Phys. 1999, 62, 969.

2. Taylor G.I., Proc. R. Soc. A, 1934, 146, 501.

3. Rallison J.M., Ann. Rev. Fluid Mech., 1984, 16, 45.

4. Milliken W.J., Leal L.G., J. Non-Newtonian Fluid Mech., 1991, 40, 355.

5. Reiss H., J. Colloid Interface Sci., 1975, 53, 61.

6. Myers D., Surfaces, Interfaces, and Colloids. Wiley, New York, 1999.

7. Ugelstad J., Hansen F.K., Lange S., Die Makromolekulare Chemie, 1974, 175, 507.

8. Tang P.L., Sudol E.D., Silebi C.A., et al., J. Appl. Polymer Sci., 1991, 43, 1059.

9. Landfester K., Tiarks F., Hentze H., et al., Macromol. Chem. Phys., 2000, 201, 1.

10. Meleson K., Graves S., Mason T.G., Soft Materials, 2005, 2, 109.

11. Graves S., Meleson K., Wilking J., et al., J. Chem. Phys., 2005, 122, 134703/1.

12. Schaflinger U., Fluid Dynamics Research, 1990, 6, 213.

13. Mason T.G., Lacasse M.-D., Grest G.S., et al., Phys. Rev. E, 1997, 56, 3150.

14. Ashcroft N.W., Lekner J., Phys. Rev., 1996, 145, 83.

15. Mason T.G., Curr. Opin. Colloid Interface Sci., 1999, 4, 231.

16. Frenkel D., Vos R.J., de Kruif C.G., et al., J. Chem. Phys., 1986, 84, 4625.

17. Liu A.J., Nagel S.R., Nature, 1998, 396, 21.

\section{Екстремальна емульсифікація: формування та структура наноемульсій}

\author{
Т.Г.Мейсон, С.Грейвс, Дж.Вілкінс, М.Й.Лін \\ 1 Факультет хімії та біохімії університету Каліфорнії \\ Лос Анджелес СА 90095 США \\ 2 Факультет фізики та астрономії університету Каліфорнії \\ Лос Анджелес СА 90095 США \\ 3 Центр ядерних досліджень Національного інституту \\ стандартів та технології, Гейтерсбург, 20899 США
}

Received July, 18, 2005, in final form November 24, 2005

\begin{abstract}
Наноемульсії є метастабільними дисперсіями нанокрапель однієї рідини, що відірвані за допомогою зсуву в іншу незмішувану рідину. Такі краплі стабілізуються відносно послідуючого об'єднання за допомогою сурфактанту. Оскільки нанокраплі не формуються спонтанно, як це може статись у ліотропній "мікроемульсійній" фазі, структура наноемульсії насамперед залежить від від історії прикладених напружень зсуву відносно відновлюваних напружень на границях розділу. Застосовуючи екстремально високі швидкості зсуву та контролюючи склад емульсії, нам вдалось створити мікроскопічні краплі аж до малого діаметру 30 нм для мікрофлюїдного процесу, що дозволяє отримувати об'ємні зразки для комерційного застосування. Після подрібнення за допомогою ультрацентрифуг з метою вироблення рівномірних крапель, ми досліджуємо структуру цих емульсій за допомогою малокутового розсіювання нейтронів при домішкових та концентрованих співвідношеннях об’ємів. Ми визначаємо структуру концентрованої наноемульсії за допомогою структурного фактору твердих кульок при подібних співвідношеннях об'ємів.
\end{abstract}

Ключові слова: емульсія, наноемульсія, краплі, наномасштаб, створення, мікрофлюїди, форм фактор, структурний фактор, подрібнення

PACS: $82.70 . K j, 61.46 .-w, 61.12 . E x$ 
